\title{
HUBUNGAN PENGETAHUAN IBU TENTANG ASI EKSKLUSIF TERHADAP PEMBERIAN MP-ASI TERLALU DINI TAHUN 2019
}

\author{
Tri Santika Manurung ${ }_{1}$, Parmiana Bangun ${ }^{2}$, Renny Sinaga ${ }^{3}$ \\ Poltekkes Kemenkes Medan ${ }^{123}$ \\ email:1trisantikacantik@gmail.com,2parmianabangun83@gmail.com,3rennysinaga.75@gmail.com
}

\begin{abstract}
World Health Organization (WHO), approximately 1.5 million children die due to improper feeding. Less than $15 \%$ of infants worldwide are given exclusive breastfeeding for four months. This study aims to determine the mother's knowledge about breastfeeding and MP-ASI in the tanjung tongah sub-district of siantar martoba pematangsiantar in 2019. This type of research is descriptive. The population in this study mothers who have babies 0-12 months. Primary data obtained through filling out the questionnaire. The sample used was 30 mothers. From the results of the study obtained based on the characteristics of the majority of respondents aged 20-35 years namely 29 mothers $(96.6 \%)$, high school education that is 21 mothers (70\%), IRT work that is 27 mothers $(90 \%)$, Javanese namely 28 mothers $(93,3 \%)$, multigravida parity, 19 mothers $(63.3 \%)$, problems in breastfeeding, namely nipple nipples, 19 mothers $(63.3 \%)$, and knowledge about exclusive breastfeeding, the most dominant, NOT GOOD knowledge, 19 mothers $(63.4 \%)$, and Knowledge about MP-ASI is the most dominant of GOOD knowledge, namely 18 mothers $(60 \%)$. Thus it is recommended to all mothers who have babies aged 0-12 months to further increase their knowledge

and insight regarding exclusive breastfeeding and MP-ASI.
\end{abstract}

Keywords: Knowledge: ASI; MP-ASI.

\begin{abstract}
ABSTRAK
World Health Organization (WHO), lebih kurang 1,5 juta anak meninggal karena pemberian makanan yang tidak benar. Kurang dari 15\% bayi di seluruh dunia diberi ASI eksklusif selama empat bulan.. Penelitian ini bertujuan untuk mengetahui pengetahuan ibu tentang ASI dan MP-ASI di kelurahan tanjung tongah kecamatan siantar martoba pematangsiantar tahun 2019. Jenis penelitian ini Deskriftif. Populasi dalam penelitian ini ibu yang memiliki bayi 0-12 bulan. Data Primer didapat melalui pengisian kuesioner. Sampel yang digunakan adalah $30 \mathrm{ibu}$ . Dari hasil penelitian didapatkan berdasarkan karakteristik mayoritas responden berumur 20-35 Tahun yaitu 29 ibu (96,6 \%), Pendidikan SMA yaitu 21 ibu (70\%), Pekerjaan IRT yaitu 27 ibu (90\%), Suku Jawa yaitu 28 ibu (93,3\%),Paritas multigravida yaitu $19 \mathrm{ibu}(63,3 \%)$, Masalah dalam menyusui yaitu Puting lecet yaitu $19 \mathrm{ibu}$ (63.3\%), dan Pengetahuan tentang ASI Eksklusif paling dominan pengetahuan TIDAK BAIK yaitu 19 ibu $(63,4 \%)$, serta Pengetahuan tentang MP-ASI paling dominan pengetahuan BAIK yaitu 18 ibu (60\%). Dengan demikian dianjurkan kepada semua ibu yang memiliki bayi usia 0-12 bulan untuk lebih meningkatkan pengetahuan dan wawasan mengenai ASI eksklusif dan MP-ASI.
\end{abstract}

Kata kunci : Pengetahuan; Asi eksklusif; MP-ASI. 


\section{PENDAHULUAN}

\section{Latar Belakang}

ASI adalah makanan bayi yang paling penting terutama pada bulan-bulan pertama kehidupan. ASI merupakan sumber gizi yang sangat ideal dengan komposisi yang seimbang dan sesuai dengan kebutuhan pertumbuhan bayi, karena ASI adalah makanan bayi yang paling sempurna baik secara kualitas maupun kuantitas. ASI sebagai makanan tunggal akan cukup memenuhi kebutuhan tumbuh kembang bayi normal sampai usia 4-6 bulan (Sulistyawati, 2009). Pemberian MP-ASI yang terlalu dini atau terlambat, dimana pemberian MP-ASI sebelum bayi berumur 6 bulan dapat menurunkan konsumsi ASI dan gangguan pencernaan/diare dan jika pemberian MP-ASI terlambat (bayi sudah lewat usia 6 bulan) dapat menyebabkan hambatan pertumbuhan anak ${ }^{(1)}$

Organisasi Kesehatan Dunia (WHO) memperkirakan, lebih kurang 1,5 juta anak meninggal karena pemberian makanan yang tidak benar. Kurang dari $15 \%$ bayi di seluruh dunia diberi ASI eksklusif selama empat bulan dan sering kali pemberian makanan pendamping ASI tidak sesuai dan tidak aman. Gangguan pertumbuhan pada awal masa kehidupan anak usia di bawah lima tahun (balita) antara lain akibat kekurangan gizi sejak dalam kandungan (pertumbuhan janin yang terhambat), pemberian makanan pendamping ASI terlalu dini atau terlambat serta tidak cukup mengandung energi dan zat gizi terutama mineral, dan tidak berhasil memberikan ASI eksklusif. ${ }^{(2)}$

Menurut data UNICEF, dari 135 juta bayi yang lahir setiap tahun di seluruh dunia, hampir 83 juta bayi tak memperoleh penyusuan yang optimal. Asosiasi ibu Menyusui Indonesia (AIMI) menjelaskan pemberian ASI selama enam bulan pertama bayi hingga dilanjutkan selama dua tahun bersama dengan pemberian makanan pendamping ASI (MPASI) yang cukup gizi menjauhkan angka kematian. ${ }^{(3)}$

Hasil SDKI 2017 Mengemukakan bahwa Angka Fertilitas Total turun dari 2,6 anak pada
SDKI 2012 menjadi 2,4 anak per wanita. Angka kelahiran menurut kelompok umur (ASFR) 15-19 mengalami penurunan dari 48 (SDKI 2012) menjadi 36 pada SDKI 2017. Kemudian terjadi peningkatan pemakaian kontrasepsi (semua cara) dari 62 persen pada SDKI 2012 menjadi 64 persen pada SDKI 2017. Persentase kebutuhan ber KB yang tidak terpenuhi (unmet need) mengalami penurunan dari 11,4 pada SDKI 2012 menjadi 10,6 persen pada SDKI 2017. Pada kematian bayi dan anak, semua angka kematian bayi dan anak hasil SDKI 2017 menunjukkan lebih rendah dibandingkan dengan hasil SDKI 2012, sedangkan pada ibu yang kehamilannya diperiksa oleh tenaga kesehatan menurun dari 95,7 persen pada tahun 2012 menjadi 93,9 pada tahun 2017 (SDKI, 2018).

Angka Kematian Bayi menjadi sesuatu yang penting untuk dicegah karena masih merupakan masalah di bidang kesehatan. Bayi merupakan investasi sumber daya manusia (SDM) untuk masa yang akan datang. Kualitas kehidupan bayi secara tidak langsung akan menjadi estimasi kualitas kehidupan bangsa di masa yang akan datang. Selain itu, AKB turut menjadi salah satu indikator dalam menilai tingkat kesejahteraan dan derajat kesehatan suatu bangsa. ${ }^{(5)}$

Bayi yang di berikan MP ASI terlalu dini mempunyai dampak risiko kontaminasi yang sangat tinggi, yaitu terjadinya gastroenteritisyang sangat berbahaya bagi bayi dan dapat mengurangi produksi ASI lantaran bayi jarang menyusui dan dapat menimbulkan terserangnya diare, batuk-pilek, dan panas dibandingkan bayi yang diberikan ASI eksklusif. Semakin bertambah umur bayi, frekuensi terserang diare, batuk-pilek, dan panas semakin meningkat Kondisi itu ternyata disebabkan oleh MP-ASI yang tidak terjaga kebersihannya, sehingga mudah terkontaminasi mikroba patogen penyebab. ${ }^{(6)}$

Hal ini sesuai dengan hasil riset terakhir dari peneliti di Indonesia menunjukkan bahwa bayi yang mendapatkan MPASI sebelum bayi berumur 6 bulan, lebih banyak terserang diare, sembelit, batuk-pilek, dan panas dibandingkan bayi yang hanya mendapat ASI eksklusif . Makanan pendamping ASI harus diberikan tepat pada waktunya, artinya bahwa semua bayi harus 
mulai mendapatkan makanan sebagai tambahan ASI dari umur 6 bulan kedepan. Makanan harus diberikan secara adekuat, yang berarti bahwa nilai nutrisi dari makanan pendamping ASI harus sama dengan ASI. Makanan harus dipersiapkan dan diberikan dengan cara yang aman, harus dipastikan memiliki resiko sekecil mungkin dari kontaminasi patogen. Makanan harus diberikan dengan cara layak secara tekstur dan jumlah yang cukup. $^{(7)}$

Hasil penelitian Maharani. O, menunjukkan bahwa faktor-faktor yang mempengaruhi ibu dalam memberikan MP-ASI pada bayi saat berumur $<6$ bulan adalah bayi yang terus menangis dan dalam pikiran ibu dianggap lapar sementara ASI tidak cukup, ibu yang bekerja sehingga tidak sempat memberi ASI, anjuran orang lain (keluarga), bidan atau rumah sakit tempat ibu melahirkan sudah memberikan susu formula sejak lahir. Jenis MP ASI yang diberikan berupa pisang, bubur instant dan bubur yang dibuat sendiri ${ }^{\left({ }^{(8)}\right.}$

Penelitian Aprilica Manggalaning Murti, (2016) yang berjudul Pengetahuan Ibu Menyusui Tentang ASI Eksklusif diwilayah Kerja Puskesmas Ngrampal Sragen ada 51 ibu menyusui dengan pengetahuan baik sebanyak $20 \mathrm{ibu}$, pengetahuan cukup 28 ibu dan pengetahuan kurang 3 ibu. ${ }^{(9)}$

Survei awal yang dilakukan peneliti bulan Januari 2019 di kelurahan tanjung tongah kecamatan siantar martoba pematangsiantar terdapat 78 orang ibu yang memiliki bayi usia 0-12 bulan dan telah dilakukan wawancara pada 43 orang ibu yang mempunyai bayi $0-12$, dan 30 orang ibu menyatakan ibu telah memberikan makanan pendamping ASI sebelum berusia 6 bulan dengan alasan pekerjaan, bayi terus menangis, dan bayi tidak pandai untuk menyusui.

Berdasarkan latar belakang diatas maka penulisan tertarik untuk melakukan penelitian dengan judul "hubungan pengetahuan ibu tentang ASI Eksklusif terhadap pemberian MPASI terlalu dini di kelurahan tanjung tongah kecamatan siantar martoba pematangsiantar".

\section{Tujuan Penelitian}

1. Untuk mengetahui Bagaimana hubungan pengetahuan ibu tentang ASI Eksklusif terhadap pemberian MP-ASI terlalu dini di kelurahan tanjung tongah kecamatan siantar martoba pematangsiantar.

2. Untuk mengetahui hubungan pengetahuan ibu tentang ASI Eksklusif terhadap pemberian MP-ASI terlalu dini di kelurahan tanjung tongah kecamatan siantar martoba pematangsiantar berdasarkan umur, pendidikan, pekerjaan, suku, paritas, masalah dalam menyusui, pengetahuan ibu tentang Makanan Pendamping ASI.

3. Untuk mengetahuip distribusi frekuensi hubungan pengetahuan ibu tentang ASI Eksklusif terhadap pemberian MP-ASI terlalu dini.

\section{Hipotesis}

Ada pengaruh faktor umur, suku, pekerjaan, pendidikan, paritas, kesehatan ibu, masalah menyusu dan pengetahuan ibu tentang ASI Eksklusif terhadap pemberian MP-ASI terlalu dini.

\section{METODE}

Jenis penelitian ini adalah penelitian Deskriptif yaitu untuk mengetahui Hubungan Pengetahuan ibu tentang ASI Eksklusif terhadap pemberian MP-ASI Terlalu dini melalui dengan rancangan penelitian cross sectional. Penelitian dilakukan di Kelurahan Tanjung Tongah Kecamatan Siantar Martoba Kota Pematangsiantar Tahun 2019. Populasi dalam penelitian adalah seluruh ibu menyusui yang memiliki bayi $0-12$ bulan berjumlah 30 orang dan seluruh populasi dijadikan objek penelitian. Metode pengumpulan data yang digunakan adalah Metode pengumpulan data adalah dengan menggunakan data primer dan data sekunder. Data Primer didapat melalui pengisian kuesioner yang disusun oleh penelitian yang berisikan pertanyaan dan pilihan jawaban yang disiapkan. Sedangkan Data sekunder didapat dari buku KIA Puskesmas Martoba Jumlah sampel yang digunakan adalah seluruh ibu menyusui yang memiliki bayi 0-12 bulan Tongah dan telah memberikan makanan pendamping ASI terlalu dini berjumlah 30 orang. Instrumen yang digunakan adalah kuesioner tentang 
pengetahuan responden tentang ASI Eksklusif dan MP-ASI dengan menggunakan skala Guttman.

\section{HASIL}

Distribusi frekuensi karakteristik ibu yang diteliti meliputi umur, pendidikan, pekerjaan, suku dan status gravida. Karakteristik dari 30 responden ibu hamil dapat dilihat pada table berikut :

Tabel 1 : Distibusi Frekuensi Karakteristik Ibu berdasarkan Umur, Pendidikan, Pekerjaan Suku, dan Status Gravida

\begin{tabular}{|c|l|c|c|}
\hline $\mathrm{N}$ & & & \\
$\mathrm{o}$ & Karakteristik & $\mathrm{n}$ & $\%$ \\
\hline 1 & Umur & & \\
& 20-30 Tahun & 29 & 96,6 \\
& 20-35 Tahun & 1 & 3,4 \\
\hline & Total & 30 & 100 \\
\hline 2 & Pendidikan & & \\
& SMP & 6 & 70 \\
& SMA & 21 & 20 \\
& Perguruan Tinggi & 3 & 10 \\
\hline & Total & 30 & 100 \\
\hline 3 & Pekerjaan & & \\
& IRT & 27 & 90 \\
& PNS & 3 & 10 \\
\hline & Total & 30 & 100 \\
\hline 4 & Suku & 2 & \\
& Batak & 28 & 93.3 \\
& Jawa & 30 & 100 \\
\hline & Total & & \\
\hline 5 & Paritas & 11 & 36.7 \\
& Primigravida & 19 & 63.3 \\
\hline & Multigravida & 30 & 100 \\
\hline & Total & & \\
\hline
\end{tabular}

Berdasarkan Karakteristik penelitian Tabel 1 diketahui dari 30 orang ibu mayoritas berusia 20-30 tahun sebanyak 29 orang (96,6\%), mayoritas ibu berpendidikan SMA sebanyak 21 orang (20\%), mayoritas ibu suku jawa sebanyak 28 orang $(93,3 \%)$, mayoritas ibu bekerja sebagai Ibu Rumah Tangga sebanyak 27 orang $(90 \%)$ dan mayoritas responden menurut paritas adalah multigravida sebanyak 19 orang $(63.3 \%)$.
Tebel 2 Distribusi Frekuensi Ibu Menyusui berdasarkan Masalah dalam Menyusui Pada Payudara di Kelurahan Tanjung Tongah Kecamatan Siantar Martoba.

\begin{tabular}{|c|c|c|c|}
\hline $\mathrm{N}$ & Macalah dalam menvucui & $n$ & $0 / 0$ \\
\hline 1 & Putting lecet & 19 & $\begin{array}{c}63 . \\
3\end{array}$ \\
\hline 2 & Payudara bengkak & 7 & $\begin{array}{c}23 . \\
3\end{array}$ \\
\hline 3 & Putting Masuk kedalam & 4 & $\begin{array}{c}13 . \\
4\end{array}$ \\
\hline & Total & 30 & 100 \\
\hline
\end{tabular}

Berdasarkan tabel 2 di atas dapat diketahui bahwa dari $30 \mathrm{ibu}$, masalah/kelainan pada payudara ibu yang paling banyak adalah Puting lecet yaitu 19 ibu (63.3\%) dan yang paling sedikit adalah ada putting susu masuk kedalam yaitu 4 ibu (13.4\%).

Tabel 3 Distribusi Frekuensi Ibu Berdasarkan Pengetahuan tentang ASI-Eksklusif Ibu di Kelurahan Tongah, Kecamatan

Siantar

Martoba.

\begin{tabular}{|c|c|c|c|}
\hline $\begin{array}{l}\mathrm{N} \\
\mathrm{O}\end{array}$ & Pengetahuan Ibu & $\mathrm{n}$ & $\%$ \\
\hline 1 & Baik & 11 & 36.6 \\
\hline 2 & Tidak Baik & 19 & 63.4 \\
\hline & Total & 30 & 100 \\
\hline
\end{tabular}

Berdasarkan tabel 3 di atas dapat diketahui bahwa dari 30 ibu pengetahuan ibu yang paling banyak adalah Tidak Baik yaitu 19 ibu $(63,4 \%)$ dan yang paling sedikit adalah Baik yaitu $11 \mathrm{ibu}(36,6 \%)$.

Tabel 4 Distribusi Frekuensi Ibu Berdasarkan Kelurahan

Pengetahuan tentang MP-ASI di

Tanjung Tongah, Kecamatan Siantar Martoba

\begin{tabular}{|c|l|c|c|}
\hline No & Pengetahuan Ibu & n & $\%$ \\
\hline 1 & Sangat Baik & 10 & 33.4 \\
\hline 2 & Baik & 18 & 60 \\
\hline
\end{tabular}




\begin{tabular}{|c|l|c|c|}
\hline 3 & Tidak Baik & 2 & 6.6 \\
\hline & Total & & \\
\hline
\end{tabular}

Berdasarkan tabel 8 di atas dapat diketahui bahwa dari 30 ibu pengetahuan ibu yang paling banyak adalah Baik yaitu $18 \mathrm{ibu}$ $(60 \%)$ dan yang paling sedikit adalah Tidak Baik yaitu 2 ibu (6,6\%).

\section{PEMBAHASAN}

Berdasarkan hasil penelitian terhadap 30 orang ibu menyusui terhadap Gambaran Pengetahuan Ibu tentang ASI Eksklusif dan MP-ASI di kelurahan tanjung tongah kecamatan siantar martoba. berdasarkan dari Gambaran Pengetahuan Tentang ASI-Eksklusif Ibu di Kelurahan Tanjung Tongah, Kecamatan Siantar Martoba di dapat hasil penelitian ditemukan dari 30 ibu menyusui dan mempunyai bayi bayi 0-12 bulan mayoritas pengetahuan ibu tentang ASI-Eksklusif yang paling banyak adalah Tidak Baik yaitu 19 ibu $(63,4 \%)$ dan yang paling sedikit adalah Sangat Baik yaitu $11 \mathrm{ibu}(36,6 \%)$. Maka dapat peneliti simpulkan pengetahuan ibu di Kelurahan Tanjung Tongah tidak baik karena kurang terpaparnya pengetahuan tentang ASI ESKLUSIF dari tenaga kesehatan maupun bidan di daerah tersebut.

Berdasarkan dari Gambaran Pengetahuan Tentang MP-ASI Ibu di Kelurahan Tanjung Tongah, Kecamatan Siantar Martoba maka hasil penelitian ditemukan dari 30 ibu menyusui dan mempunyai bayi bayi $0-12$ bulan mayoritas pengetahuan ibu yang paling banyak adalah Baik yaitu $18 \mathrm{ibu}(60 \%)$ dan Sangat Baik yaitu $10 \mathrm{ibu}(33,4 \%)$ serta Tidak Baik yaitu $2 \mathrm{Ibu}$ $(6,6 \%)$. Maka dapat peneliti simpulkan pengetahuan ibu tentang MP-ASI di kelurahan tanjung tongah baik karena banyak ibu yang telah mengetahui tentang MP-ASI dari kebiasaan keluarga.Pendapat Notoatmodjo jika pengetahuan ibu baik tentang pemberian MPASI maka pemberian ASI eksklusif menjadi baik dan jika pengetahuan ibu tidak baik tentang pemberian MP-ASI maka pemberian ASI eksklusif menjadi tidak baik. Hal ini sesuai dengan teori bahwa pengetahuan atau kognitif merupakan domain yang sangat penting dalam membentuk tindakan seseorang.Ibu menyusui yang tidak dibekali pengetahuan yang cukup tentang teknik menyusui yang benar dan manajemen laktasi, inisiasi praktek menyusui dan lamanya pemberian ASI, serta faktor risiko praktek pemberian susu formula.

\section{KETERBATASAN PENELITIAN}

1. Penelitian ini hanya mengambil sampel pada waktu dan jumlah yang terbatas, sehingga untuk penelitian selanjutya sebaiknya meneliti dnegan jumlah sampel yang lebih banyak.

2. Pada penelitian ini hanya mengukur pengetahuan ibu tentang ASI ekskusif melalui distribusi kuesioner.

\section{KESIMPULAN}

Setelah dilakukan penelitian tentang "Gambaran pengetahuan ibu tentang ASI dan MP-ASI di kelurahan tanjung tongah kecamatan siantar martoba pematangsiantar tahun 2019" dapat diambil kesimpulan sebagai berikut :

1. Berdasarkan Pengetahuan Ibu tentang ASIEksklusif Mayoritas Pengetahuan ibu yang paling banyak adalah Tidak Baik yaitu 19 ibu $(63,4 \%)$ dan yang paling sedikit adalah Sangat Baik yaitu 11 ibu (36,6\%), maka Pengetahuan Ibu tentang ASI-Eksklusif di Kelurahan Tanjung Tongah berpengetahuan TIDAK BAIK.

2. Berdasarkan Pengetahuan Ibu tentang MPASI Mayoritas Pengetahuan ibu yang paling banyak adalah Baik yaitu $18 \mathrm{ibu}$ $(60 \%)$ dan Sangat Baik yaitu 10 ibu $(33,4 \%)$ serta Tidak Baik yaitu 2 ibu (6,6\%) maka Pengetahuan Ibu tentan MPASI di Kelurahan Tanjung Tongah berpengetahuan BAIK.

3. Berdasarkan Karakteristik Ibu keselurahan 
diketahui

dalam mengetahui . Berdasarkan Usia

29 ibu (96,6\%) berusiaa20-35

Tahun.Berdasarkan Pendidikan diketahui 21 ibu (70\%) Pendidikan terakhir SMA. Berdasarkan

Pekerjaan diketahui 27 ibu (90\%) berkerja dirumah. Berdasarkan Suku diketahui 28 ibu $(93,3 \%)$ bersuku jawa.Berdasarkan Paritas diketahui 19 ibu (63,3\%) merupakan ibu Multigravida.Berdasarkan masalah dalam menyusui diketahui $19 \mathrm{ibu}$ (63,3\%) pernah memiliki masalah putting susu lecet saat menyusui.

\section{DAFTAR PUSTAKA}

1. Maryunani, Anik. 2012. Inisiasi Menyusui Dini, ASI Ekslusif dan Manajemen Laktasi. Jakarta: Trans Info Media.

2. Simanjuntak, E. 2013. Dampak Pemberian Makan Pendamping ASI Terlalu Dini, http://www.psychologymania.com/,Jurnal Kesehatan.

3. Santoso, L.W. 2014. AIMI Dorong Pemerintah Untuk Dukung Pemberian ASI Untuk Bayi, www.antaranews.com.

10. Notoatmodjo, S. (2012). Metodologi penelitian kesehatan (Cetakan VI) [JOUR]. Jakarta: Penerbit PT. Rineka Cipta.
4. SDKI, 2017. http://sdki.bkkbn.go.id/files/buku/2017ID HS.pdf

5. Al-Shookri A, Al-Shukaily L, Hassan F, Al-Sheraji S, Al-Tobi S.2011. Effect of Mothers Nutritional Knowledge and Attitudes on Omani Children's Dietary Intake. Oman Medical Journal; 2 (4):2537.

6. Laila, N., \& Riyanti, E. (2019). Peningkatan pemberian ASI dan MP-ASI melalui kader.

7. Suryono. (2014). Bayi Sehat berkat ASI Eksklusif. Jakarta: PT Elex Komputindo.

8. Maharani, O. (2016). Pemberian Makanan Pendamping ASI Dini Berhubungan dengan Kejadian Diare pada Bayi umur 0 12 bulan di Kecamatan Dampal Utara, Tolitoli, Sulawesi Tengah. Jurnal Ners Dan Kebidanan Indonesia. https://doi.org/10.21927/jnki.2016. 4(2).84-89

9. Aprilica. M. M. (2016). Pengetahuan Ibu Menyusui Tentang ASI Eksklusif di Wilayah Kerja Puskesmas Ngrampai Sragen. Jurnal Kesehatan "Samodra Ilmu” Vol. 07 No. 02. https://www.neliti.com/id/publications/137 505/pengetahuan-ibu-menyusui-tentangasi-eksklusif

11. Hidayat A. A. A. 2007. Metode Penelitian Kebidanan dan Teknik Analisa Data,Salemba Medika: Jakarta. 
Jurnal IImiah Pannmed (Pharmacyst, Analyst, Nurse, Nutrition, Midwivery, Environment, Dental Hygiene)

Vol. 15 No.1 Januari - April 2020 
